I Universidade Federal do Rio Grande do Sul (UFRGS), Programa

de Pós-Graduação em Sociologia, Porto Alegre, RS, Brasil

jaymegomesnt@gmail.com

https://orcid.org/0000-0003-I56I-900I

Jayme Gomes Neto'

\title{
A TEORIA SOCIAL NO SÉCULO XX: NOVAS "VINTE LIÇÕES"
}

Joas, Hans \& Knöbl, Wolfgang. (2017). Teoria Social:

vinte lições introdutórias. Tradução: Raquel Weiss.

Petrópolis: Vozes.

Teoria Social: vinte lições introdutórias constitui um empreendimento intelectual de larga escala, fruto de um trabalho de quase duas décadas protagonizado por dois reconhecidos teórisocial. Resultado de uma série de aulas proferidas por ocasião da passagem de Hans Joas pela Universidade de Chicago em I985, o manuscrito viria a ser revisado e expandido nas décadas seguintes com a ajuda de seu ex-aluno Wolfgang Knöbl, coautor do livro. Publicado originalmente em 2004 - e traduzido para inglês em 2009 - o texto logo se tornou uma referência importante no campo da sociologia teórica, constituindo, segundo Eisenscrítica análise do desenvolvimento da teoria social da segunda metade do século XX". Em 20I7, a obra finalmentadt, "talvez a mais compreensiva e te chega ao Brasil pela Editora Vozes. A publicação, que conta com a tradução de Raquel Weiss, põe agora ao alcance do público brasileiro um texto de primeira linha que promete cobrir uma importante lacuna editorial. Sua sofisticação conceitual, aliada à capacidade de síntese dos autores, servirá de ferramenta valiosa tanto a estudantes iniciantes como a pesquisadores e professores.

Em linhas gerais, o livro de Joas e Knöbl pode ser considerado a contraparte europeia da obra homônima Twenty lectures - publicada por Jeffrey Alexander em I987. Se, por um lado, os autores são menos centrados na "lógica teórica" do que Alexander (I987) - o que faz com que sua reconstrução pareça, às vezes, mais fragmentada ou mesmo dotada de motivações metateóricas menos aparentes -, por outro, 
essa abertura vem acompanhada de uma surpreendente amplitude de escopo. Com quase o dobro de páginas, as vinte lições propostas por Joas e Knöbl cobrem não só o desenvolvimento da sociologia norte-americana no pós-Segunda Guerra Mundial, como era o caso de Alexander, mas também os mais importantes desdobramentos da teoria social europeia.

Nesse sentido, a estrutura geral do livro pode ser dividida em duas grandes partes: nas primeiras oito lições, os autores abarcam basicamente o mesmo período analisado por Alexander, isto é, aquele da hegemonia parsoniana durante os anos I940 e i 950 (lições II, III e IV) e as respostas críticas que emergiram em solo americano nas décadas seguintes, tais como o neoutilitarismo (lição V), o interacionismo simbólico (lição VI), a etnometodologia (lição VII) e a teoria do conflito (lição VIII); na segunda parte do livro, a reconstrução volta-se para a teoria social europeia por meio da análise de algumas figuras centrais que emergem nos anos I970 e I 980, tais como Habermas (lições IX e X), Luhmann (lição XI), Giddens (lição XII) e Bourdieu (lição XV), assim como para uma série de desdobramentos ou tradições igualmente importantes naquele contexto: estruturalismo e pós-estruturalismo (lição XIV), teorias antiestruturalistas (lição XVI), teoria feminista (lição XVII), teóricos da (crise da) modernidade (lição XVIII) e neopragmatismo (lição XIX). Essa mudança de eixo da teoria sociológica - que se volta novamente para a Europa depois dos anos I970 - constitui, aliás, uma das teses centrais do livro.
A despeito de tais diferenças estruturais, Joas e Knöbl não deixam de seguir Alexander em alguns pontos importantes. Eles compreendem, tal como seu colega estadunidense, que a tarefa científica é animada por um esforço que oscila permanentemente entre um "ambiente empírico" (observações) e um "ambiente metafísico" (pressupostos teóricos e metateóricos) (p. 24) e que, no caso da teoria sociológica, esse movimento se direciona à resposta de três questões fundamentais: "o que é a ação social?"; "o que é a ordem social?"; e "o que determina a mudança social?" (p. 33). Eis o eixo de leitura do livro: as teorias analisadas são confrontadas a todo momento com essas três grandes questões.

Estabelecida essa grade geral (lição I), os autores - mais uma vez em convergência com Alexander (I987: 22 I Io) - reconhecem a figura de Talcott Parsons como ponto de partida privilegiado da história sociológica do século XX, motivo pelo qual são dedicadas a ele três lições inteiras. A lição II volta-se à contextualização e à análise da primeira grande obra de Parsons (I937), A estrutura da ação social. Nesse livro fundador da sociologia moderna, Parsons não apenas acabaria por estabelecer o cânone da sociologia clássica (Durkheim e Weber), mas também o famoso "quadro geral de referência" da ação, contra e em referência ao qual se elaborariam os principais desenvolvimentos da teoria sociológica subsequente.

O esquema "Ação/Ordem/Mudança" acompanha as análises da obra parsoniana. $\mathrm{O}$ argumento da lição III mostra 
como a teoria da ação parsoniana, pouco a pouco cede lugar a um funcionalismo normativo no qual a ordem sobrevém e, de certo modo, elimina-a como elemento dotado de autonomia analítica. Na lição IV, os autores mostram como esse movimento desemboca em uma teoria dos sistemas que, a despeito de sua enorme sofisticação, parece conceber a mudança social em meio a um problemático evolucionismo de fundo. No fim das contas, o verdadeiro ponto alto da teoria parsoniana teria sido sua teoria da ação, a partir do que a obra do sociólogo americano experimentaria uma espécie de declínio sofisticado.

Nas lições subsequentes (V-VIII) Joas e Knöbl mostram como o neoutilitarismo, o interacionismo simbólico, a etnomedotologia e a teoria do conflito identificam e respondem, embora sempre de maneira parcial, a certas antinomias do pensamento parsoniano, seja elaborando e reformulando seu esquema da ação, seja identificando problemas em suas análises macrossociológicas. No entanto, para além da funcionalidade dessa narrativa, colocar as coisas desse modo parece estratégico aos olhos dos autores por pelo menos dois motivos - que só se evidenciam nas lições subsequentes.

Em primeiro lugar, a montagem histórica centrada na teoria da ação parsoniana aparece como mote de uma radical crítica ao funcionalismo compreendido como uma espécie de anti-humanismo estéril; crítica que reaparecerá várias vezes ao longo do livro, principalmente nas lições dedicadas a Giddens (XII) e aos antiestru- turalistas franceses (XVI). A respeito destes últimos, aliás, é digno de nota o fato de que autores por vezes marginalizados em relação aos grandes debates da teoria social (Catoriadis e Ricoeur) tenham sido resgatados de maneira tão entusiasmada. Coadunam-se ainda com essa orientação geral da obra a não aparição de Robert Merton - talvez a ausência mais significativa do livro ao lado de Norbert Elias -, as duras críticas feitas à chamada teoria da modernização (XIII) e o tratamento relativamente menos simpático e mais superficial dedicado a Luhmann (XI) quando comparado a seu concorrente alemão Habermas (IX e X). E mesmo este último, que aparece como figura destacada que teria fornecido talvez a maior contribuição à teoria da ação desde Parsons - e não por acaso o único, além de Parsons, a receber mais de uma lição -, é criticado por ter cedido demasiadamente às investidas de Luhmann, incorporando a linguagem sistêmica de maneira problemática em seu quadro teórico.

Uma segunda dimensão estratégica da montagem feita por Joas e Knöbl, que só se torna mais clara ao final do livro, diz respeito à tentativa de mostrar como a ação social, de Parsons a Habermas, tem sido trabalhada num mesmo paradigma (teleológico-racional). Em sua primeira reformulação moderna, por meio do "quadro geral de referência", Parsons teria chamado a atenção para os elementos normativos, em contraposição à dimensão puramente utilitária da ação. Esse movimento teria obrigado a uma reformulação do utilitarismo clássico por par- 
te de todas as teorias que, de um modo ou outro, ainda buscavam insistir nos aspectos instrumentais e estratégicos da ação social. Segundo Joas e Knöbl, esse foi o caso do neoutilitarismo, da chamada teoria do conflito e, para espanto de alguns, do próprio Bourdieu (XV) que, a despeito de suas críticas ao utilitarismo, não se encontraria inteiramente livre dessa tendência. Em todos esses casos, o que estaria em jogo seria sempre um parâmetro de racionalidade que conceberia a existência de metas (instrumentais ou normativas) preconcebidas (de maneira mais ou menos consciente). Por fim, até mesmo Habermas, que expande a compreensão da ação de modo a abarcar seu potencial dialógico-comunicativo, não deixaria de partir, na base de seu esquema, de um modelo de ação racional e teleológico.

Ao contar a história da teoria da ação dessa forma, os autores preparam o terreno para uma "reestruturação fundamental dos princípios subjacentes à teoria social dominante" (p. 546) mediante um programa de pesquisa capaz de focar sua dimensão propriamente expressiva e criativa. Trata-se de uma vertente subterrânea que encontra herdeiros no pragmatismo clássico (tais como Mead e Dewey), notadamente ausentes do cânone parsoniano; que se vale de contribuições de precursores e aliados discutidos ao longo do livro, tais como Blumer, Garfinkel, Castoriadis e Touraine; que encontra no contexto filosófico contemporâneo uma aliança com as obras de Rorty, Taylor e, sobretudo, Putnam; e que, por fim, se realizaria de maneira mais bem acabada, no interior da teoria social contemporânea, no neopragmatismo (XIX) de Bernstein e, principalmente, do próprio Joas.

Insistir nas motivações subjacentes à reconstrução feita pelos autores, no entanto, não significa argumentar em nome de uma suposta imparcialidade - algo que os autores não pretendem e que sequer seria possível num empreendimento desse tipo. Tal insistência é, antes, resultado da tentativa de fornecer a um projeto dessa magnitude uma unidade que de outro modo seria de difícil visualização. Pois o projeto de Joas e Knöbl é, de fato, resultado de um monumental esforço de síntese, no qual são abarcadas com propriedade, inteligência e erudição as mais diversas correntes das ciências sociais. Por fim, vale dizer que mesmo quando adentram correntes em relação às quais mantêm uma posição crítica, os autores nunca cedem a reducionismos ou leituras apressadas, prova de seriedade e honestidade intelectual notáveis.

Recebida 5/4/2018 Aprovada 3/5/2018 


\section{REFERÊNCIAS BIBLIOGRÁFICAS}

Alexander, Jeffrey C. (1987). Twenty lectures. Sociological theory since World War II. New York: Columbia University Press.

Parsons, Talcott. (I937). The structure of social action. New York: McGraw Hill.

Jayme Gomes Neto é mestre em sociologia pela Universidade de São Paulo (USP) e doutorando em sociologia pela Universidade Federal do Rio Grande do Sul (UFRGS). 